\title{
The reporting of theoretical health risks by the media: Canadian newspaper reporting of potential blood transmission of Creutzfeldt-Jakob disease
}

\author{
Kumanan Wilson*1,2, Catherine Code 3 , Christopher Dornan ${ }^{4}$, \\ Nadya Ahmad ${ }^{5}$, Paul Hébert ${ }^{2,3,5}$ and Ian Graham²,5
}

Address: ${ }^{1}$ Departments of Medicine and Health Policy, Management and Evaluation, University of Toronto, Toronto, Canada, ${ }^{2}$ University of Ottawa Centre for Clinical Transfusion Research, University of Ottawa, Ottawa, Canada, ${ }^{3}$ Department of Medicine, University of Ottawa, Ottawa, Canada, ${ }^{4}$ School of Journalism and Communication, Carleton University, Ottawa, Canada and ${ }^{5}$ Ottawa Health Research Institute, Ottawa, Canada

Email: Kumanan Wilson* - kumanan.wilson@uhn.on.ca; Catherine Code - cathycode@hotmail.com;

Christopher Dornan - chris_dornan@carleton.ca; Nadya Ahmad - a1949501@admin.uottawa.ca; Paul Hébert - phebert@ohri.ca;

Ian Graham - igraham@ohri.ca

* Corresponding author

Published: 05 January 2004

BMC Public Health 2004, 4:I

This article is available from: http://www.biomedcentral.com/I47/-2458/4/I

(c) 2004 Wilson et al; licensee BioMed Central Ltd. This is an Open Access article: verbatim copying and redistribution of this article are permitted in all media for any purpose, provided this notice is preserved along with the article's original URL.
Received: 08 September 2003

Accepted: 05 January 2004

\begin{abstract}
Background: The media play an important role at the interface of science and policy by communicating scientific information to the public and policy makers. In issues of theoretical risk, in which there is scientific uncertainty, the media's role as disseminators of information is particularly important due to the potential to influence public perception of the severity of the risk. In this article we describe how the Canadian print media reported the theoretical risk of blood transmission of Creutzfeldt-Jakob disease (CJD).

Methods: We searched 3 newspaper databases for articles published by 6 major Canadian daily newspapers between January 1990 and December 1999. We identified all articles relating to blood transmission of CJD. In duplicate we extracted information from the articles and entered the information into a qualitative software program. We compared the observations obtained from this content analysis with information obtained from a previous policy analysis examining the Canadian blood system's decision-making concerning the potential transfusion transmission of CJD.

Results: Our search identified 245 relevant articles. We observed that newspapers in one instance accelerated a policy decision, which had important resource and health implication, by communicating information on risk to the public. We also observed that newspapers primarily relied upon expert opinion (47 articles) as opposed to published medical evidence (28 articles) when communicating risk information. Journalists we interviewed described the challenges of balancing their responsibility to raise awareness of potential health threats with not unnecessarily arousing fear amongst the public.
\end{abstract}

Conclusions: Based on our findings we recommend that journalists report information from both expert opinion sources and from published studies when communicating information on risk. We also recommend researchers work more closely with journalists to assist them in identifying and appraising relevant scientific information on risk. 


\section{Background}

In recent years the public has been exposed to information about several potential emerging health risks. These have included the potential risks associated with new infectious conditions, genetically modified foods, vaccines, bioterrorism and biotechnology [1]. In many instances the information on the likelihood of these risks is uncertain and considered to be theoretical. Nevertheless the public's perception of these risks has the potential to influence the eventual development of government policy.

The news media play an important role in conveying information on theoretical health risks to the public and thus influencing the perception of these risks. However, the reporting of theoretical risks offers many challenges. Journalists face difficulties in interpreting non-experimental data and in comparing the different methods of reporting risk that are found in medical studies. Important questions also arise as to the relative weight newspapers should apply to expert opinion versus published medical evidence in reporting of risks [2].

The theoretical risk of acquiring Creutzfeldt-Jakob disease (CJD) through blood transmission provides a useful model to study media reporting of risk and its influence on the development of policy. CJD was the first major infectious challenge to nations' blood systems after HIV and hepatitis $C$ and therefore gained a high degree of public attention in many Western countries.

The emergence of a variant form of CJD in the United Kingdom (UK), linked to Bovine Spongiform Encephalopathy (Mad Cow disease), contributed to the media attention given to this health issue [3]. Several nations' blood systems have struggled to address the issue of potential blood-borne transmission of CJD in an environment characterized by a high level of public concern over the matter as well as uncertainty over whether CJD can be transmitted by blood products $[4,5]$. The media have the potential to significantly influence policy decisions concerning the potential blood transmission of CJD by informing the public of this theoretical risk

\section{Creutzfeldt-Jakob Disease}

CJD is a rare incurable neurological disorder that inevitably results in death within one to two years. It is an unusual condition as it does not occur as the consequence of a bacterium or virus but rather an infectious protein or "prion". Individuals who acquire CJD develop movement disorders, followed by a progressive dementia. In 1996, a variant form of the condition (vCJD) was described that was linked to Bovine Spongiform Encephalopathy (BSE) or Mad Cow disease. This condition differs from the classical form by affecting younger individuals and presenting with primarily psychiatric symptoms. It is suspected that vCJD develops in individuals who have eaten beef from cows affected by BSE [6].

The majority of cases of CJD likely arise from sporadic mutations in brain proteins of previously healthy individuals. In a minority of cases CJD has been shown to be transmitted by transfer of neurological tissue from individuals affected by the condition to unaffected individuals. The most frequent form of this transfer has been administration of human growth hormone derived from the pituitary glands of individuals who had died of CJD [7]. While no conclusive evidence exists of transmission of CJD via blood products, the theoretical possibility of this transmission has concerned several nations' blood systems. This has led to policy decisions to prevent blood donations from individuals with CJD or those at risk of this condition.

The Media, Risk Communication and Influence on Policy The media plays an important role at the interface of science and policy. One model of policy making specifically describes the media's role in the policy process as that of a key disseminator of scientific information [8]. This model describes how information is generated by researchers and then disseminated by advocacy networks and the media. This information is ultimately picked up by individuals formally involved in the policy process, such as government officials, and those informally involved, such as citizens and stakeholder groups. The interpretation of this information is influenced by the value systems of the individuals receiving the information.

The media's role as a disseminator of scientific information is particularly important in areas of risk. The mechanism by which the media present scientific information on risk to the public can influence risk perception. For example, the choice of the media to report relative as opposed to absolute risks associated with a potential harmful agent can magnify the public's perception of the risk associated with exposure to the agent [9]. However, frequent media reporting of a risk, regardless of the content of the reporting, can lead to an increased ability to recall the risk from memory. According to the "availability heuristic" this increased ability to recall a risk increases an individual's perception of the likelihood of the risk occurring [10]. This observation has led to investigations of whether the media's coverage of health risks accurately reflects the likelihood of the risks occurring [11,12]. Findings from these studies have led to the accusation that the media exaggerate some risks and ignore others [13]. However, other analyses argue that the media in general support currently held views on risk due to their reliance on experts in reporting these risks [14]. The appropriateness 
of media reporting of health risks and its potential impact on policy remains a matter of debate [15].

\section{Methods}

Our general objective in this study was to describe the media's role as a purveyor of scientific information in the policy process concerning potential blood transmission of CJD in Canada. We chose to focus on the role of newspaper reporting in particular. The specific objectives of this study were to (1) describe general characteristics of how major Canadian daily newspapers reported stories related to the potential blood transmission of CJD, (2) determine if, and by what mechanism, this reporting influenced the policy process, (3) determine how newspaper journalists conveyed information on theoretical risk to the public and (4) describe some of the challenges journalists' face when communicating information on risks of this nature.

To achieve all of these objectives we combined information obtained from a content analysis of newspaper articles with information obtained from a previous policy analysis.

\section{Content Analysis}

To characterize the reporting of CJD and blood supply stories, and to determine how information on risk was reported, we conducted a content analysis of major Canadian newspapers [16]. We searched six major Canadian daily newspapers between January 1990 and December 1999 using the Canadian Business and Current Affairs, Infomart and Infoglobe databases. The selected papers included the oldest English-language national newspaper (Globe and Mail - 2002 weekly circulation of 2085 115) [17], as well as papers representing the 5 largest cities in Canada (Montreal Gazette-999 874, Vancouver Sun-1 211 808, Calgary Herald-838 048, Ottawa Citizen-1 021 282, Toronto Star-3 337 467). These papers had the highest circulation in their respective cities with the exception of the Montreal Gazette which was the highest circulation English newspaper in its city. We searched the databases using the following key words: (CJD or Creutzfeldt) and blood. Two authors independently reviewed all retrieved articles and identified reports relating to blood transmission of Creutzfeldt-Jakob disease. Independently and in duplicate, we extracted data from these articles and categorized them under the following headings: newspaper, date, location of article, author of article, individuals cited, organizations cited, event reported, reporting of evidence, and slant of reporting. Reporting of evidence was classified under the following headings: general statement of risk, expert opinion, animal evidence, case report, and epidemiological study. All disagreements were resolved by consensus. The QSR.NUDIST qualitative software was used to analyze the data and identify patterns of reporting [18].

\section{Semi-structured interviews and review of documents}

To determine whether news stories impacted the policy agenda and, if so, the mechanism by which this occurred, we relied on information obtained from a separate parallel policy analysis we conducted examining CJD and blood policy related decisions [19]. This analysis specifically focused on 2 CJD and blood supply decisions: a 1995 decision to withdraw blood from a donor with CJD and the 1999 decision to defer donations from individuals who had spent 6 months in the UK between 1980 and 1996 due to concerns about variant CJD. Related policy decisions were also examined. We obtained information for this analysis from a review of minutes of meetings, policy papers and other relevant documents. We supplemented this document review by conducting 32 semistructured interviews with key informants who were involved in the policy process. During the interviews we asked individuals to describe how decision-making took place and what they believed were the key factors that influenced the decision-making process. We specifically asked individuals how external factors, such as the media, influenced the development of policy. All interviews were taped, transcribed and coded using QSR.NUDIST software. We extracted all references to the media in the interviews, both from coded text and from a text word search and identified those statements that referred to the media's role in the policy process. From this information we identified links between media reports and the development of policy.

\section{Interviews with journalists}

Four of the interviews we conducted were with journalists. These interviews explored in more detail the role of journalists in reporting stories pertaining to the potential blood transmission of CJD. We asked journalists their perceptions of how the policy processes unfolded, the role of the media in the policy process, how the media should report such issues of theoretical risk and how the media obtains scientific information on issues of risk. From these interviews we developed themes that characterized the journalists' perspectives on reporting stories of this nature.

\section{Results}

We identified and analyzed 245 relevant articles pertaining to CJD and the blood supply. The initial reporting began in July 1995 (Figure 1). Seven articles had banner headlines and 23 articles were on the front page. The majority of stories were news reports (207 articles), although information pieces, human-interest stories and editorials were also written on the subject (Table 1). Seventy-six articles provided an opinion on the quality of decision making with the majority of these (64) describing some form of criticism of the process (Table 3 ). 


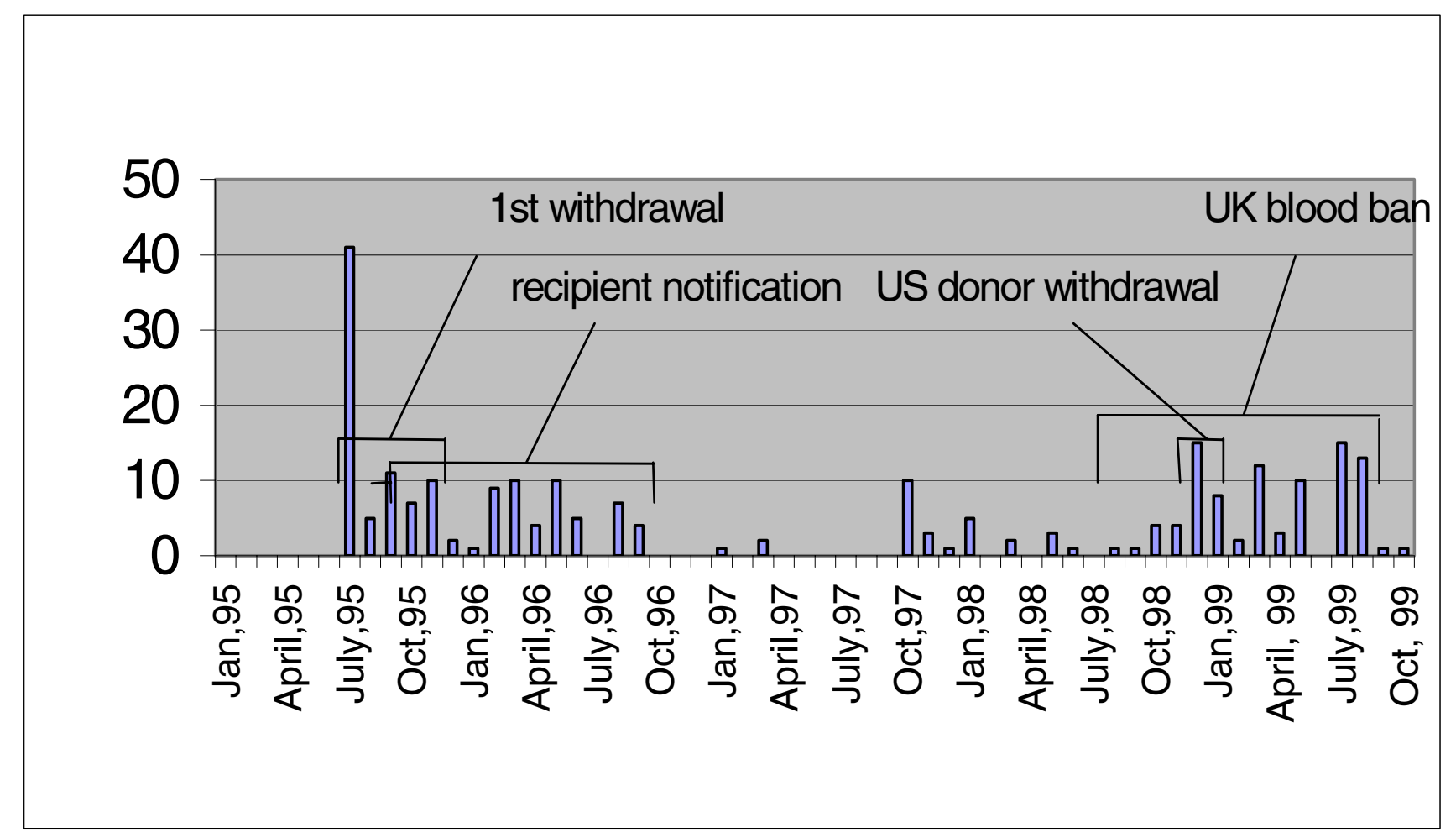

Figure I

Number of CJD-related articles published per month between 1995 and 2000. $\mathbf{x}$-axis: Publication month $\mathbf{y}$-axis: Number of articles published

Table I: Characteristics of Articles

\begin{tabular}{lclc}
\hline Location of article & \# of articles (\% of total) & Article type & \# of articles (\% of total) \\
\hline Banner Headline & $7(3)$ & News report & $207(84)$ \\
Other front page & $23(9)$ & Information piece & $15(6)$ \\
Other front section & $180(73)$ & Human interest & $10(4)$ \\
Not front section & $35(14)$ & Editorial/ letter to editor & $19(8)$ \\
\hline
\end{tabular}

*Some articles classified as two article types

Table 2: Major Events Reported

\begin{tabular}{|c|c|c|c|c|}
\hline Major Events Reported & $\underset{*}{\# \text { of articles (\% of total) }}$ & Banner Headline & Other Front Page & Other Front Section \\
\hline Ist blood withdrawal & $70(29)$ & 3 & 8 & 42 \\
\hline Recipient notification & $27(\mathrm{II})$ & 1 & 4 & 12 \\
\hline $\begin{array}{l}\text { US CJD donor blood } \\
\text { quarantine }\end{array}$ & $31(13)$ & 1 & 0 & 27 \\
\hline UK blood ban & $35(14)$ & 0 & 3 & 26 \\
\hline
\end{tabular}

*Other stories make up the remaining $23 \%$ of articles 
Table 3: Critiquing of decision-making

\begin{tabular}{lllllll}
\hline Slant of Reporting & Total \# of articles & \multicolumn{3}{c}{ Sources of Criticism/Praise } \\
\cline { 3 - 6 } & & Paper/author & advocacy group & Individual/ victim & expert & Unidentified \\
\hline Critical of decision-making* & 64 & 12 & 28 & 25 & 12 & 2 \\
Supported decision-making & 12 & 0 & 7 & 3 & 2 & 0 \\
\hline
\end{tabular}

* Some articles had multiple sources of criticism

\section{Major Events Reported}

Newspapers focused on 4 major CJD and blood supply related stories. Newspaper reporting of CJD and blood supply issues began on July 11, 1995. A series of stories described the potential new threat of CJD to the Canadian blood supply as well as several withdrawals of blood obtained from donors with CJD that were carried out to protect Canadians from this risk (29\% of all articles, July 1995 to November 1995). Newspaper stories later focused on the controversies surrounding whether recipients of blood from these donors should be notified of the potential risk of developing CJD (11\% of all articles, September 1995 to September 1996). Beginning in December of 1998 a series of newspaper stories covered the quarantine of blood that was obtained from an American donor with a suspected variant form of CJD (13\% of all articles, December 1998 to April 1999). Also in 1998 newspapers began covering stories that led to the decision to ban blood donations from individuals who had traveled to the UK for 6 months between 1980 and 1996, due to concerns that these individuals may be harbouring variant CJD (14\% of all articles, August 1998 to September 1999) (Table 2).

\section{Impact of Newspaper Reporting on Blood Policy}

We identified one instance in which newspaper reporting appeared to directly influence the development of policy. A July 11, 1995 newspaper story reported statements made by an American hematologist, Dr Nathan Kobrinsky, testifying at the Krever Inquiry into the Canadian blood system that CJD could be the next major threat to the Canadian blood system. Canadian Press, the national wire service, reported these statements and 4 of the 6 newspapers that we examined published the story. The newspaper stories ran headlines that referred to the emergence of a "new killer virus" [20] (Table 5). A Vancouver woman subsequently read the story and notified the Red Cross that her father, a frequent blood donor, had recently died of CJD. In response, the Red Cross voluntarily recalled all blood products that potentially contained this donor's blood.

The impact of this story on the decision to embark upon the blood withdrawal is clearly supported by transcribed reports from the Krever Inquiry [21]. In these reports the Director of the Canadian Red Cross Society, the organization that was responsible for collecting, testing and distributing blood products, made the statement:

"There was wide-spread media coverage of what Dr. Kobrinsky said. And if I remember right, it's my understanding that the daughter of the patient in Vancouver was aware of the media coverage, and because the father had been just diagnosed with this disease with this long name which nobody could forget, she was, you know --- that's why she called the centre"

The blood withdrawal triggered by the newspaper story had important consequences. It was, at the time, the largest in Canadian history, created shortages of certain blood products and was estimated to have cost $\$ 11$ million.

\section{Risk Communication}

In addressing the potential risks of classical and variant CJD blood transmission, the majority of articles $(60 \%$, 148 articles) directly stated or alluded to the fact that there was no evidence that CJD could be transmitted by the blood system. Twenty-six percent of articles (64) made reference to the potential or theoretical risk of CJD blood transmission. Articles often described the risk of transmission as follows: "There's never been a reported case of Creutzfeldt-Jakob disease being transmitted via blood transfusions or plasma products, but medical research hasn't ruled the possibility out" [22].

Most articles relied upon expert opinion when communicating information on risk of blood transmission of CJD (47 articles, $19 \%$ of total). Of these reports, the majority (40 articles) implied that CJD blood transmission was not possible. The expert opinion in 22 of these articles was from scientists or physicians affiliated with the government or a stakeholder group. In 28 articles, expert opinion was derived from independent scientists or physicians (Table 4).

Of all 245 articles, only $11 \%$ ( 28 articles) referred to some form of scientific study evidence. Of these 28 articles, 11 referred to animal evidence, 10 of which suggested blood 
Table 4: Types of Evidence Reported by Newspapers

\begin{tabular}{lccc}
\hline Type of Evidence & \# of articles (\% of total) & $\begin{array}{c}\text { Supporting potential CJD } \\
\text { Transmission by blood }\end{array}$ & $\begin{array}{c}\text { Against potential CJD Transmission } \\
\text { by blood or unsure }\end{array}$ \\
\hline General Statement of Risk & $212(87)$ & 64 & 148 \\
Expert Opinion* & $47(19)$ & 9 & 40 \\
Basic Science/Animal Study & $11(4)$ & 10 & 1 \\
Case Report & $12(5)$ & 12 & 0 \\
Epidemiological Study & $5(2)$ & 0 & 5
\end{tabular}

*Two articles reported expert opinion both for and unsure/against transmission

Table 5: Sample Headlines from Major News Stories Reported

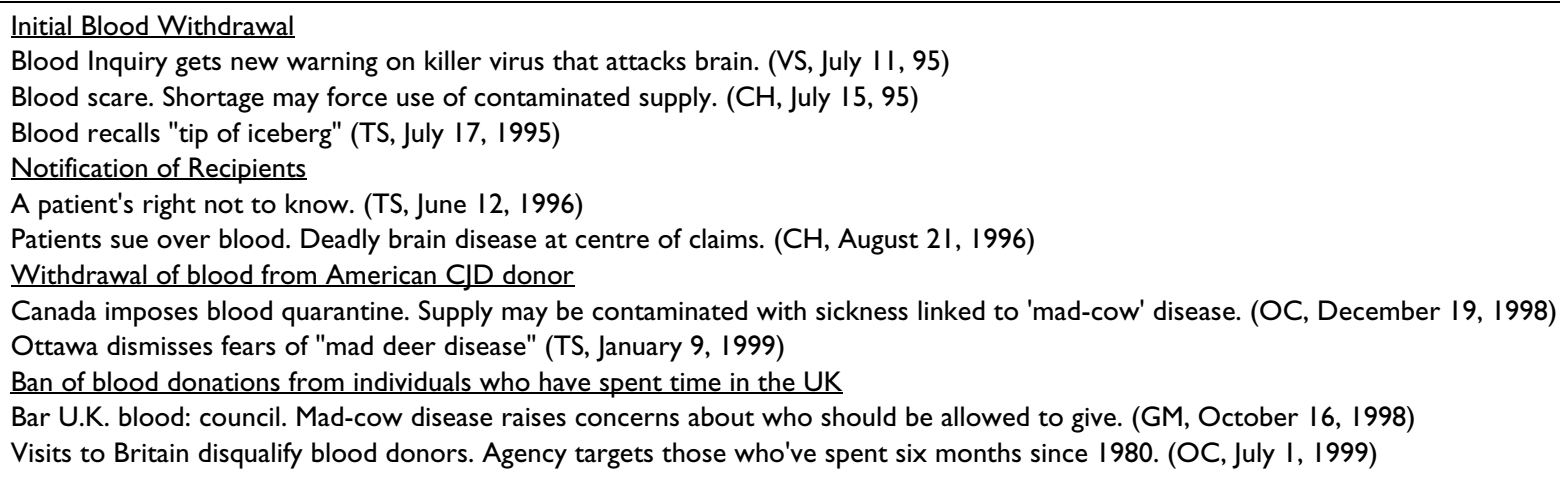

(VS = Vancouver Sun, $\mathrm{CH}=$ Calgary Herald, $\mathrm{TS}=$ Toronto Star, OC = Ottawa Citizen, GM = Globe and Mail)

transmission was possible. Twelve of the 28 references to scientific evidence referred to a single case report that suggested the possibility of blood transmission of classical CJD [23]. Only 5 of the 28 references to scientific evidence referred to epidemiological studies: one reference to epidemiological studies in general, one to a 1993 case-control study, two to a study of hemophiliacs and one reference to a cohort study of veterans [24,25]. All references to epidemiological studies indicated a lack of evidence for classical CJD transmission via blood products.

\section{Perspectives on the role of the media in CJD/blood supply decisions}

Several themes emerged from our interviews with journalists and other individuals involved in the policy process regarding reporting of CJD and blood supply stories. A perception existed among members of the media that they may have previously failed in their responsibility to raise public awareness of the risk of blood transmission of hepatitis C and HIV. Journalists stated that this perception was partly responsible for the high degree of attention that the potential risk of CJD to the blood supply received in 1995. These views are reflected in the following statement made by one of our respondents; "Journalists felt very much in the past that they had done a disservice about playing down the risk (of transfusion transmission of hepatitis C and HIV) and so what they did was they went overboard during the Krever Inquiry".

In deciding how to report the potential blood transmission of CJD, journalists struggled with balancing their responsibility to raise awareness of risk with their responsibility to not unnecessarily alarm the public. One journalist we interviewed stated; "I think you have to be very responsible and careful when you are dealing with something that is a theoretical risk. You have to be very careful with your words because you don't want to panic people but you still want to raise awareness of these issues."

Journalists described to us the challenges in reporting scientific information on theoretical risk specifically on an unusual form of infections such as CJD. One reporter stated "The journalists we interviewed explained that the time and resource limitations they face make it difficult for them to keep abreast of important medical studies related to the stories they are covering. Expert opinion was considered to be more accessible and understandable. Journalists also stated that they would desire a closer 
working relationship with academics. One journalist specifically commented; "If someone in the academic field sees a story emerging that they think the media doesn't know enough about or if there is an angle we are not covering properly, I wish they'd call." However, another journalist stated that relying upon researchers can itself be problematic as they may be attempting to promote their area of research and thus sensationalize issues of risk.

\section{Discussion}

The potential blood transmission of CJD serves as a useful model to study media reporting of theoretical health risks. Blood transmission of CJD occupies a high "risk space" among the public due to its potentially catastrophic nature and the considerable scientific uncertainty concerning the risk [26]. In addition it is a risk over which the individual has little control and is occurring in a field in which public trust has been damaged, both of which further contribute to public fear of the risk [27]. The media, as an important purveyor of information in the policy process, can elevate such risks to the forefront of public opinion. Alternatively, they can refrain from drawing public attention to such risks [28].

In examining how Canadian newspapers reported the risk of potential blood transmission of CJD we found that in at least one instance, the 1995 blood withdrawal decision, a newspaper article played a critical in the development of policy. In this instance the media did not influence policy through a traditional agenda setting function, as the potential infectivity of blood products with CJD was already on the policy agenda in Canada [29]. Instead, the newspaper story primarily served to accelerate the policy process, forcing a decision to be made earlier than it normally would have been. The mechanism by which this was done was by raising awareness of risk amongst the public by communicating information on risk provided by an expert source.

The question arises as to why the policy process was so susceptible at this time to the influence of a newspaper story. Some possible explanations include the fact that the blood system was under considerable scrutiny due to the ongoing Krever Inquiry. Uncertainty about the risk of CJD transmission due to lack of evidence also placed the blood system in a position where it could not refute claims of potential infectivity of blood products. The lack of an existing policy governing the management of blood products from donors with CJD also contributed to the blood system being susceptible at this time to the impact of a newspaper report.

In further examining the role of the print media as an information purveyor, we observed that newspaper articles primarily relied upon expert opinion reports as opposed to published scientific evidence when communicating information on risk to the public. In particular, only 5 of 245 articles examined referred to epidemiological studies. There were no references to 2 large case-control studies that did not show an association between blood transfusions and development of CJD. Both were published at the time that the US CJD donor and UK blood donation bans were receiving prominent newspaper coverage [30,31]. However, in general expert opinion reports supported epidemiological evidence in suggesting no risk of transmission. Reports of lower level scientific evidence, such as case reports and basic science studies, in contrast, were more likely to support the possibility of blood transmission of CJD.

The reliance of newspapers upon expert opinion to communicate information on risk may have resulted from several factors. CJD blood transmission is a challenging epidemiological area in which there has been difficulty in interpreting the existing research [32]. In addition, most of the research on this topic has shown no association between CJD and blood transfusion and there is a tendency of newspapers to not publish accounts of negative studies [33]. Qualitative descriptions of risk, such as those found in expert opinion statements, have also been demonstrated to be better understood by the public than quantitative descriptions [34]. There are, however, important advantages of having newspapers report scientific evidence. Such reporting protects the public from biases and agendas that may be inherent in expert opinion statements and allows the public to formulate their own opinions on issues of risk. In particular, some journalists have previously expressed the view that relying upon inaccurate expert opinion was what led to the failure of the Canadian media to raise the awareness of the public of the potential risk of blood transmission of HIV and hepatitis $C$ [35]. Another advantage of reporting published medical evidence is that it amplifies the dissemination of evidence to the general research community [36].

In a 1998 national survey, $46 \%$ of Canadians stated they using a major daily newspapers a "great deal" to obtain information, second only to television. In addition, $61 \%$ of Canadians stated they wanted to see more reporting on health [37]. Thus obtaining a further understanding of the role of the media in reporting health risks is essential. The observations of this study of newspaper reporting of one particular risk provide important messages that are of relevance to print media reporting of current debates concerning other high "risk space" theoretical health risks. These include the theoretical risks associated with genetically modified foods, xeno-transplantation and the use of other new biotechnologies. Reporting of risks of this nature offer many challenges as revealed by the journalists we interviewed. Journalists must decide when a theoreti- 
cal risk warrants reporting, interpret scientific information on this risk and determine how to communicate information on this risk to raise public awareness and not arouse unnecessary fear.

\section{Conclusions}

Journalists face many challenges in reporting theoretical health risks, as demonstrated by this study. Based on the results of our study we would recommend that when the media reports theoretical risks, clear statements should be made that the risk is actually theoretical and not formally documented. The reporting of these risks should combine published evidence with expert opinion. When published evidence is provided, the source of the evidence should be presented where possible to give the reader the option to review the original study.

Reporters face several obstacles to achieve these objectives including potentially lacking expertise in appraising evidence and the time pressures of filing stories. To overcome these obstacles we would encourage a closer working relationship between the media and the research community. The research community should be aware of the many constraints faced by journalists including time and lack of in depth knowledge of a content area. Researchers can assist members of the media in understanding evidence and make them aware of new evidence as it arises. Journals can also improve the uptake of research by the lay press by press-releasing articles, although the media should not rely solely on press releases due to their selective reporting of study findings [38]. Providing journalists with formal training on how to interpret medical evidence on causation would also assist them in reporting stories on theoretical health risks.

\section{Competing interests}

None declared.

\section{Authors' Contributions}

KW designed the study, conducted the searches, identified articles, extracted data and wrote the final manuscript. CC identified articles and extracted data. CD assisted in the design of the study and provided content knowledge expertise on the interaction of media and science. NA assisted in the extraction and classification of data. PH assisted in the design of the study and provided critical revisions to the manuscript. IG assisted in the design of the study and provided critical revisions to the manuscript. All authors approved the final manuscript.

\section{Acknowledgments}

This study was supported by a grant from the Canadian Institutes of Health Research. The authors would like to acknowledge the contribution of Dr. Andreas Laupacis for his assistance in the design of the policy analysis, information from which informed this study, and librarians Alexandra Davis and
Nina Bursey who assisted us with searching the newspaper databases and pulling the articles.

\section{References}

I. Petrie K, Wessely S: Modern Worries, New Technology, and Medicine. BMJ 2002, 324:390-391.

2. Singer E, Endreny E: Reporting on Risks: How the Mass Media Portray Accidents, Diseases, Disasters, and Other Hazards. New York: Russell Sage Foundation 1993.

3. Will R, Ironside J, Zeidler M, Cousens S, Estibeiro K, Alpérovitch A, Poser S, Pocchiari M, Hofman A, Smith P: A New Variant of Creutzfeldt-Jakob Disease in the UK. Lancet 1996, 347:921-925.

4. Health Canada: Donor Exclusion to Address Theoretical Risk of Transmission of Variant CJD Through the Use of Commercial Blood Products, Directive D99-02. Therapeutic Products Programme. Health Canada: Ottawa 1999.

5. Department of Health: Further Precautionary Measures on Blood Products Announced, Press release on CJD/BSE. Department of Health: United Kingdom 98/076 1998.

6. Cashman N: A Prion Primer. CMAJ 1997, 157:|38|-1385.

7. Brown P: Environmental Causes of Human Spongiform Encephalopathy,. in Methods in Molecular Medicine: Prion Diseases Edited by: Ridley R, Baker H. Humana Press Inc.: Totowa; 1996: I 39- I 54.

8. Lomas J: Connecting Research and Policy. Canadian Journal of Policy Research 2000, I: I 40-144.

9. Abbasi K: Headlines: More Perilous Than Pills? BMJ 1998, 316:82.

10. Tversky A, Kahneman D: Judgement Under Uncertainty: Heuristics and Biases. Science 1974, I85: I I 24- I I3I.

II. Frost K, Frank E, Maiback E: Relative Risk in the News Media: A Quantification of Misrepresentation. Am Journal Public Health 1997, 87:842-845.

12. Combs B, Slovic P: Newspaper Coverage of Causes of Death. Journalism Quarterly 1979, 56:837-843.

13. Soumerai S, Ross-Degnan D, Kahn J: Effects of Professional and Media Warnings About the Association Between Aspirin Use in Children and Reye's Syndrome. Milbank $Q$ 1992, 70: $155-182$.

14. Freudenberg W, Coleman C, Gonzales J, Helgeland C: Media Coverage of Hazard Events: Analyzing the Assumptions. Risk Analysis 1996, 16:31-42.

15. Wåhlberg A, Sjöberg L: Risk Perception and the Media. Journal of Risk Research 2000, 3:31-50.

16. Paalman M: How to Do (Or Not to Do) ... Media Analysis for Policy Making. Health Policy Plan 1997, I 2:86-91.

17. Canadian circulation database: Canadian Newspaper Association [http:l /www.cna-acj.ca/client/cna/ult.nsf/ccsearch]. December 6, 2003

18. QSR.NUD*IST. Qualitative Research \& Solutions Pty. Ltd 1997.

19. Wilson KHP, Laupacis A, Dornan C, Ricketts M, Ahmad N, Graham I: A Policy Analysis of Major Decisions Related to Creutzfeldt-Jakob Disease and the Blood Supply. CMAJ 200I, 165:59-65.

20. McDougall D: Blood Inquiry Gets New Warning on Killer Virus That Attacks Brain,. in Vancouver Sun 1995, Vancouver:A4.

21. Krever H: Commission of Inquiry on the Blood System in Canada. Final Report. Canadian Government Publishing: Ottawa 1997:1015-1021.

22. Canadian Press: Blood Scare: Shortage May Force Use of Contaminated Supply,. in Calgary Herald 1995, Calgary:A3.

23. Creange A, Gray F, Cesaro P, Adle-Biassette H, Duvoux C, Cherqui D, Bell J, Parchi P, Gambetti P, Negos J: Creutzfeldt-Jakob Disease After Liver Transplantation. Ann Neurol 1995, 38:269-272.

24. Esmonde T, Will R, Slattery J, Knight R, Harries-Jones R, de Silva R, Matthews W: Creutzfeldt-Jakob Disease and Blood Transfusion. Lancet 1993, 341:205-207.

25. Evatt B, Austin H, Barnhart E, Schonberger L, Sharer L, Jones R, DeArmond S: Surveillance for Creutzfeldt-Jakob Disease Among Persons With Hemophilia. Transfusion 1998, 38:817-820.

26. Slovic P: Perception of Risk. Science 1987, 236:280-285.

27. Gray GM, Ropeik D: Dealing with the Dangers of Fear. The Role of Risk Communication. Health Affairs 2002, 21: 106-I I6.

28. Otten A: The Influence of the Mass Media on Health Policy. Health Aff(Millwood) 1992, I I: I I I- I I8. 
29. McCombs M, Shaw D: The Agenda-Setting Function of the Mass Media. Public Opinion Quarterly 1972, 36:176-187.

30. Van Dujin C, Delasnerie-Laupretre N, Masullo C, Zerr I, de Silva R, Wientjens D, Brandel J-P, Weber T, Bonavita V, Zeidler M, Alpérovitch A, Poser S, Granieri E, Hofman A, Will R: Case-Control Study of Risk Factors of Creutzfeldt-Jakob Disease in Europe During 1993-1995. Lancet 1998, 35 I: I08I-1085.

31. Collins S, Law M, Fletcher A, Boyd A, Kaldor J, Masters C: Surgical Treatment and Risk of Sporadic Creutzfeldt-Jakob Disease: A Case-Control Study. Lancet 1999, 353:693-697.

32. Wilson K, Code C, Ricketts M: The Risk of Acquiring Creutzfeldt-Jakob Disease from Blood Transfusions: Systematic Review of Case-Control Studies. BMJ 2000, 321:17-19.

33. Koren G, Klein N: Bias Against Negative Studies in Newspaper Reports of Medical Research. JAMA 1991, 266:1824-|826.

34. Konheim C: Risk Communication in the Real World. Risk Anal 1988, 8:367-373.

35. Picard A: The Gift of Death: Confronting Canada's TaintedBlood Tragedy. Toronto: HarperCollins Publishers Ltd 1998.

36. Philips D, Kanter E, Bednarczyk B, Tastad P: Importance of the Lay Press in the Transmission of Medical Knowledge to the Scientific Community. New Engl J Med I99I, 325: I I80-I I 83.

37. Canadians and the news media. Canadian CorporateNews and the Angus Reid Group Inc. Toronto, ON. . MARCH I2, 1998

38. Entwistle V: Reporting Research in Medical Journals and Newspapers. BMJ 1995, 31 0:920-923.

\section{Pre-publication history}

The pre-publication history for this paper can be accessed here:

http://www.biomedcentral.com/1471-2458/4/1/prepub

Publish with Bio Med Central and every scientist can read your work free of charge

"BioMed Central will be the most significant development for disseminating the results of biomedical research in our lifetime. "

Sir Paul Nurse, Cancer Research UK

Your research papers will be:

- available free of charge to the entire biomedical community

- peer reviewed and published immediately upon acceptance

- cited in PubMed and archived on PubMed Central

- yours - you keep the copyright 